\title{
Estimation of Estuary Phytoplankton using a Web-based Tool for Visualization of Hyper-spectral Images
}

\author{
Vladimir J. Alarcon, John van der Zwaag, Robert Moorhead \\ GeoResources Institute, Mississippi State University \\ alarcon@gri.msstate.edu,vander@gri.msstate.edu and rjm@gri.msstate.edu
}

\begin{abstract}
The development of web-based tools for visualization and processing of hyper-spectral images has been slow. Memory and processing capabilities of personal computers may have precluded the development of web-based tools. However, fast access to remote databases, increasing microprocessors' speed, and grid portals that provide interconnection between remote nodes sharing data and computing resources, make possible remote exploration and analysis of hyper-spectral data cubes. This paper presents a web-based visualization tool for exploring MODerate Resolution Imaging Spectroradiometer (MODIS) data cubes. It provides capabilities for individual pixel's reflectance-spectra visualization, onthe-fly per-pixel calculation and visualization of chlorophyll-a and phytoplankton-carbon concentration values. The web-based interface also generates Normalized Difference Vegetation Index images from the multi-spectral information contained in MODIS datasets. The tool is applied to estimate phytoplankton concentrations in the Saint Louis Bay estuary (Mississippi). Chlorophyll-a estimations produced by the web-based tool compare well with in-situ measurements from a field survey performed during August 2001. Phytoplankton concentrations are calculated using those estimations of chlorophyll-a concentrations generated by the web-based tool. The higher spatial resolution provided by the interface allowed estimating constituents concentrations at geographical locations near the coast.
\end{abstract}

\section{Introduction}

Phytoplankton are microscopic plants, or algae, suspended in the water column of several different types of water bodies. Estuaries and lakes are common habitat for phytoplankton colonies. Phytoplankton biomass in aquatic ecosystems can be used as an indicator of water quality and ecosystem health [1].
Chlorophyll-a is a pigment associated with coastal and inland water bodies' phytoplankton and its potential as an indicator for estimating biomass of phytoplankton has been investigated extensively. For example [2] and [3] studied the relationship between chlorophyll-a and phytoplankton-carbon. Those studies concluded that it is possible to monitor chlorophyll-a (in many estuaries) for crops of phytoplankton, and that chlorophyll-a, is a rapid method to estimate the amount of living particulate plant matter, such as standing-cropphytoplankton. Over the years, chlorophyll-a has become a principal measure of the amount of phytoplankton present in a water body [1].

Already in 1989 it was shown that remote sensing can complement and extend chlorophyll-a measurements and provide data of improved temporal and spatial resolution, leading to a better understanding of phytoplankton dynamics in terms of the chlorophyll distribution in Chesapeake Bay [4]. Currently, NASA's Ocean Biology Processing Group (OBPG) provides Level-3 merged chlorophyll data, derived from Seaviewing Wide Field-of-view Sensor (SeaWiFS) and Moderate Resolution Imaging Spectroradiometer (MODIS) Aqua, for daily, 8-day, monthly, seasonal and annual time periods [5]. Level 3 data consist of data values mapped on uniform space-time grid scales, usually with some completeness and consistency [6].

However, the above described chlorophyll-a datasets are provided in spatial resolutions that may not be optimal for watershed hydrology and water quality studies at the watershed scale. Current data resolutions correspond to $4 \mathrm{~km}$ and $9 \mathrm{~km}$ grids. Figure 1.1 shows an example of the NASA's OBPG-generated chlorophyll-a image for the Gulf of Mexico, for summer, 2006 and 4-km resolution. The figure clearly shows that modelers interested in chlorophyll-a values for estuaries in the Mississippi-Alabama coasts (such as Mobile Bay and Saint Louis Bay, for example) will have only regional chlorophyll-a estimates at hand. Since MODIS data spatial resolution range from $250 \mathrm{~m}$ 
to $1000 \mathrm{~m}$, there is potential for producing ocean color estimations at those grid sizes.

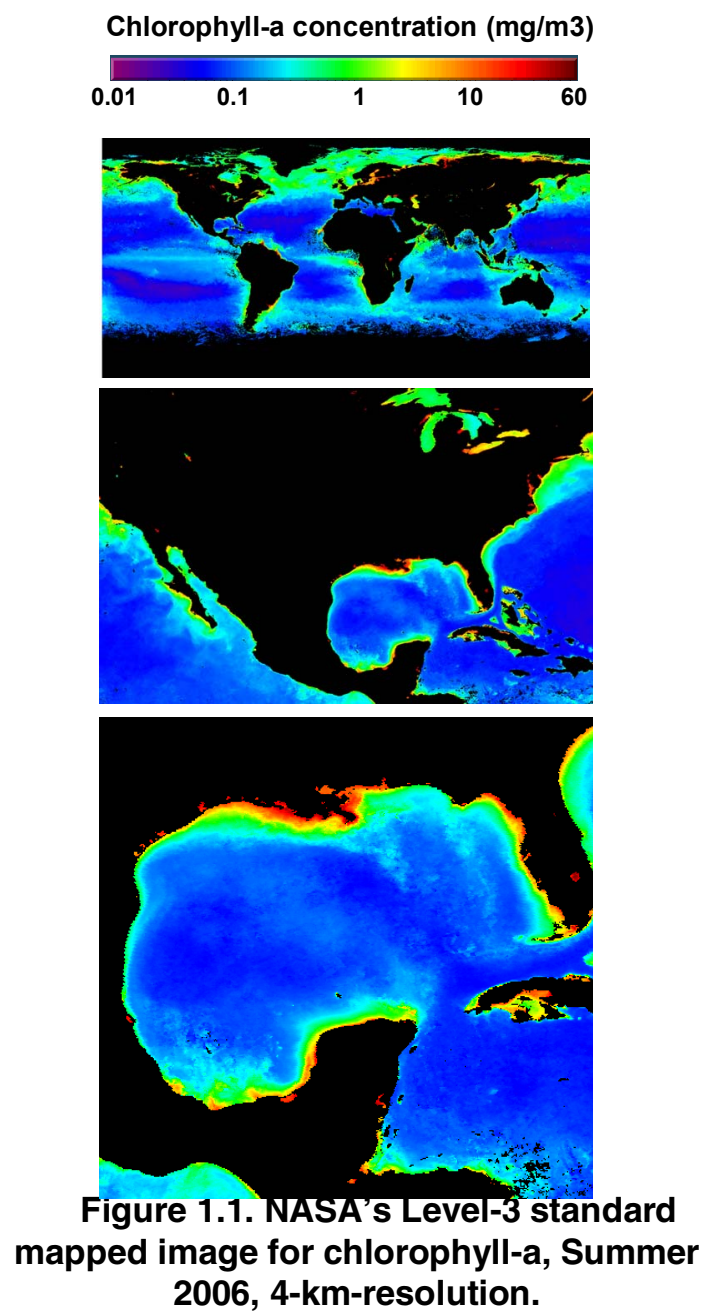

There are several algorithms for estimation of chlorophyll-a from remotely sensed spectral reflectance values. [7], [8] and [9] provide detailed guidelines for calculation of estimates of chlorophyll-a. [9] and [10] provide basis for estimation of phytoplankton-carbon from chlorophyll-a values.

The importance of chlorophyll-a and phytoplankton-carbon concentrations in water quality modeling is well documented. For example, the water quality algorithm of the Water Quality Analysis Simulation Program (WASP) has phytoplankton concentrations (in the stream or estuary) as the key factor for other constituent estimations (see Figure 1.2). The phytoplankton concentrations, in turn, are estimated from chlorophyll-a concentrations provided by the model user at user-specified boundaries and times.

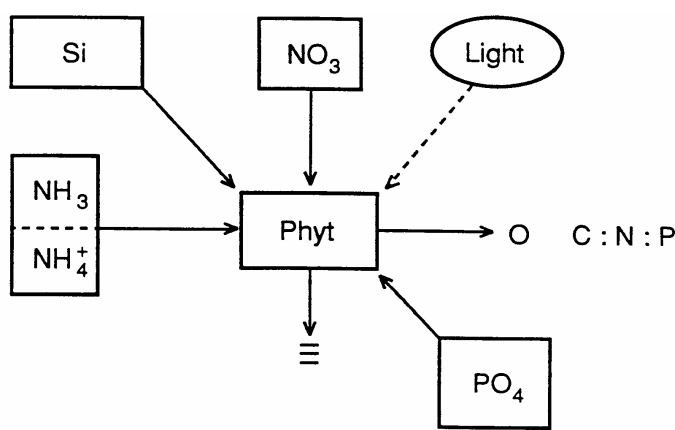

Figure 1.2. Phytoplankton and nutrients. All nutrient constituents (NO3, NH3, and PO4) and dissolved oxygen are linked through phytoplankton (after [10]).

The unstructured grid finite-volume water quality model implemented in the Satilla River Estuary Water Quality Management System [11] also uses phytoplankton-carbon concentrations as central ingredient in the calculation of other water quality constituents. Figure 1.3 illustrates the role of phytoplankton-carbon for this model.

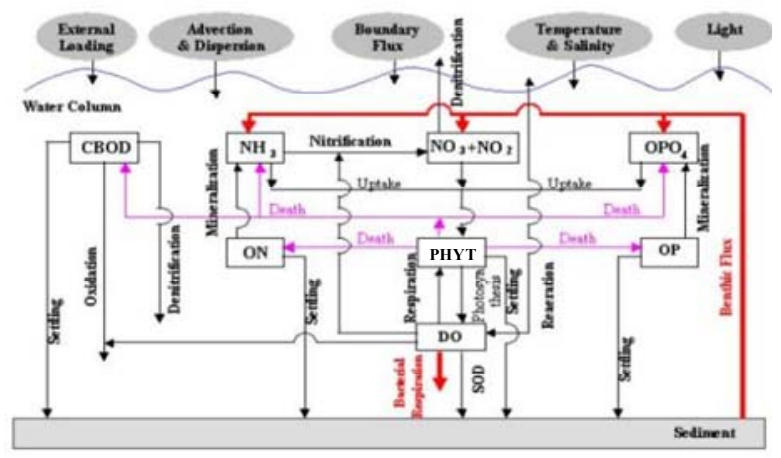

Figure 1.3. Phytoplankton-carbon role in water quality modeling (after [11]).

This research presents a web-based tool for visualization of MODIS spectral reflectance datasets. The tool is provided with per-pixel estimation of chlorophyll-a concentrations features (among other imaging capabilities). The web-based visualization system has been customized to also provide phytoplankton-carbon concentration values. The tool is applied to estimating chlorophyll-a and phytoplankton for the estuary located in the Saint Louis Bay watershed (Mississippi Gulf Coast). 


\section{Methods}

\subsection{Web-based tool}

The web-based tool presented in this research is based in previous web-based tools developed for simulation and visualization of low resolution synthetic hyper-spectral images [12].

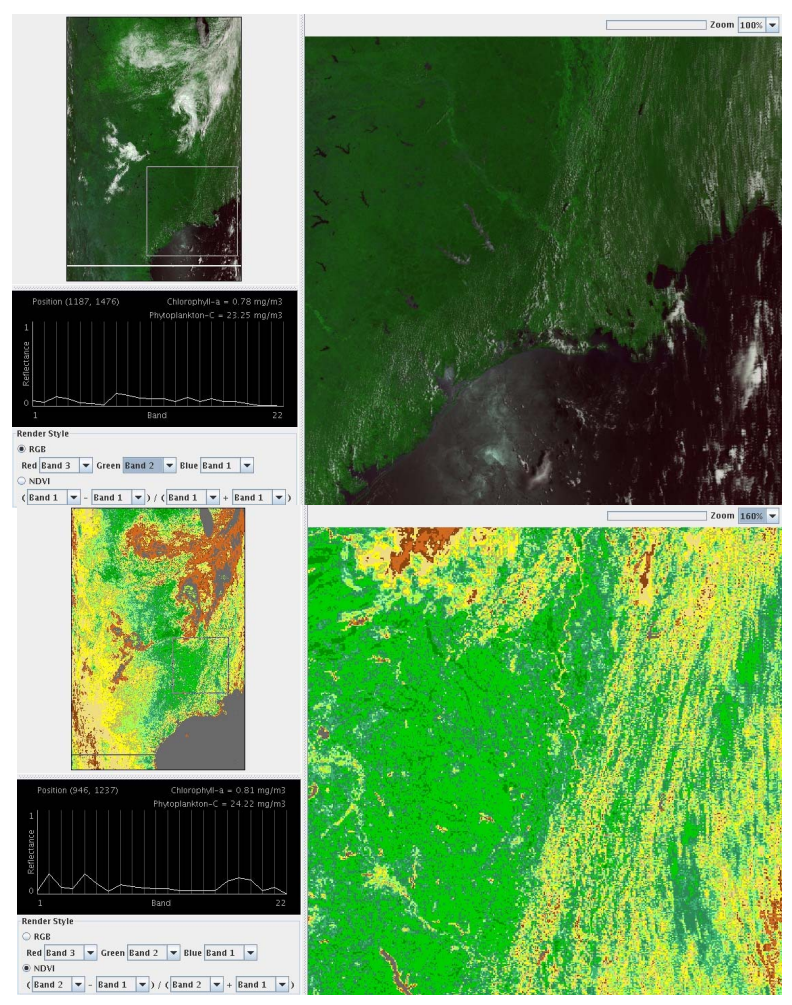

Figure 2.1. Web-based tool for visualization and processing of MODIS datasets. Normal view (upper) and NDVI image (lower).

The new tool (developed for this research) has greatly enhanced spatial and spectral resolution (see Figures 2.1 and 2.2). It has been tailored to read .geotiff files of the type of MODIS multi-spectral datacubes. However, the tool is not limited to displaying and processing MODIS-like data; it can process any multi-spectral or hyper-spectral data cube as long as it is in geotiff format. The interface displays two panning windows with zoom capabilities. Spectral reflectance curves are displayed, on-the-fly, as the cursor browses either of the panning windows. The tool also has capabilities for generating Normalized Difference Vegetation Index (NDVI) images for identification of vegetated areas.
As an application to the objectives of this research, the web-based tool provides immediate calculation of per-pixel chlorophyll-a and phytoplankton-carbon concentrations values in $\mathrm{mg} / \mathrm{m}^{3}$ (see Figure 2.2). Algorithms for calculation of those parameters are detailed in section 2.3 .
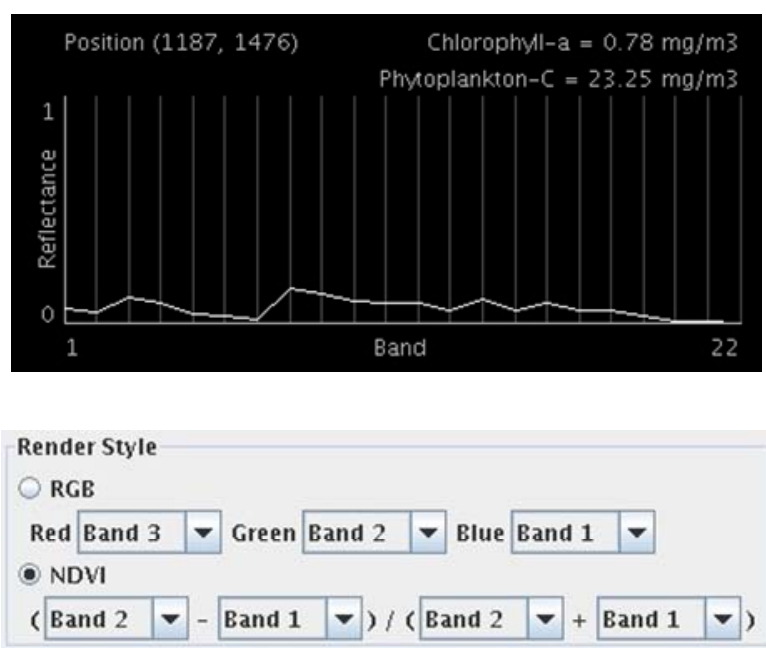

Figure 2.2. Spectral reflectance curve and control panel of the web-based tool.

\subsection{Spectral reflectance and chlorophyll-a data}

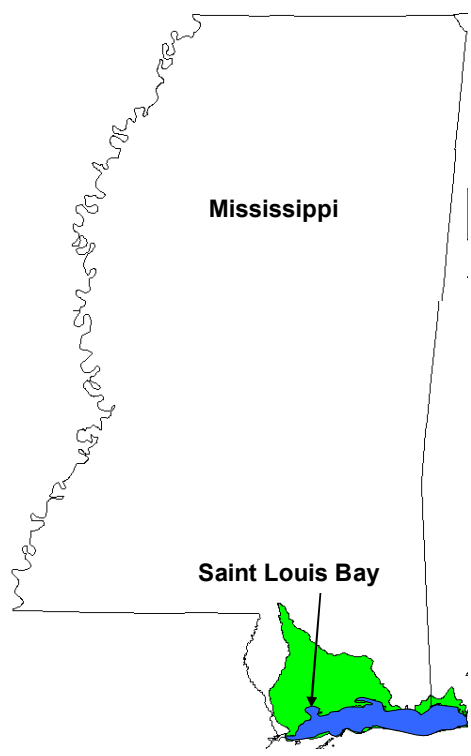

Figure 2. 3. Location of chlorophyll-a data collection and MODIS data coverage.

MODIS MOD02 spectral reflectance data from the NASA's Goddard Earth Sciences Distributed Active Archive Center (GES-DAAC) were retrieved for the dates: August 28 through 30, 2001, for the area shown 
in Figure 2.3. The dates were selected to coincide with a water quality field survey made during those days by the Mississippi Department of Environmental Quality (MDEQ) [15]. The chlorophyll-a data collected by MDEQ was done at the mouth of the Saint Louis Bay estuary (see Figure 2.3).

\subsection{Chlorophyll-a calculation}

The algorithms for estimation of chlorophyll-a concentrations in water bodies developed by the Ocean Color Team for MODIS and are well documented in [13]. This research applies those algorithms for estimation of chlorophyll-a concentrations in the study area. The MODIS algorithm uses spectral reflectance from bands 9 (438-448 nm), 10 (483-493 nm), and 12 $(546-556 \mathrm{~nm})$. The following equation relates chlorophyll-a concentrations to reflectance values at those bands.

$$
c h l-a=10^{\left(0.283-2.753 \cdot R+1.457 \cdot R^{2}+0.659 \cdot R^{3}-1.403 \cdot R^{4}\right)} .
$$

In the equation above, the term $R$ is the maximum of the logarithmic ratios: $R_{1}=\log ($ Band $9 /$ Band 12), and $R_{2}=\log \left(\right.$ Band 10/Band 12). Therefore, $R=\max \left\{R_{1}, R_{2}\right\}$.

Phytoplankton-carbon estimations can be done from chlorophyll-a data using stoichiometric ratios available in the literature. [14] provides a methodology for phytoplankton-carbon estimation from chlorophyll-a values.

Elemental analysis of blue-green algae, overall phytoplankton population, and estimates of cell composition based upon field data [14] provide a range of 23 to 30 for ratios of phytoplankton-carbon to chlorophyll-a. In this research, a ratio of 30 is used for phytoplankton estimations.

\section{Results}

Figure 3.1 shows chlorophyll-a concentration values estimated using the web-based tool and MODIS multispectral data, compared to actual field measurements of chlorophyll-a conducted by MDEQ during August $2001\left(29^{\text {th }}\right.$ and $\left.30^{\text {th }}\right)$. The chlorophyll-a values are in milligrams per cubic meter $\left(\mathrm{mg} / \mathrm{m}^{3}\right)$ and should be read at the right-hand side scale.

As seen in Figure 3.1, the MODIS algorithms (implemented in the web-based tool) tend to slightly underestimate chlorophyll-a concentrations for the study area. However, the differences seem to be negligible in the context of water quality modeling, where concentrations are usually managed (for numerical calculations) in milligrams per liter. Nevertheless this research is presenting an initial exploration of chlorophyll-a concentrations estimation.
Future studies will look at seasonal and yearly trends for calibration of the technique. Figure 3.1 also shows calculated phytoplankton-carbon concentrations using the chlorophyll-a estimated data. Although there are no field measurements to compare these concentration values, they are within value ranges measured in previous studies [16].

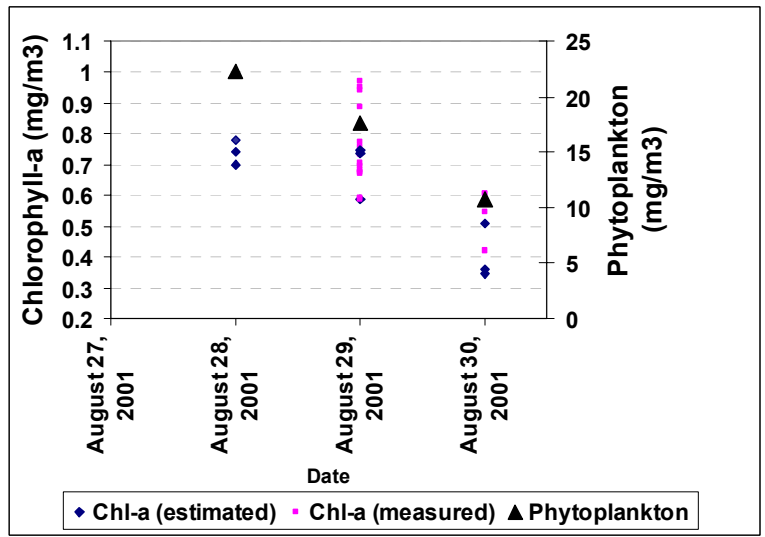

\section{Figure 3.1 Comparison of chlorophyll-a concentration values (estimated versus measured). Phytoplankton-carbon concentrations are also shown.}

\section{Conclusions}

The web-based tool developed for this research has proven to be very effective for visualization of MODIS datasets. The chlorophyll-a and phytoplankton concentrations calculated by the algorithm implemented in the tool, have allowed identifying concentrations at higher spatial resolutions (250 to $1000 \mathrm{~m}$ ) than data resolutions currently available through the NASA's Ocean Color group (4 km, 9 km). The comparison of the tool's estimations of chlorophyll-a to measured data was successful. However, further studies are needed to validate the methodology for chlorophyll-a and phytoplankton concentrations calculation. Especially the later since no field data were available to compare the estimated concentration values. Future studies will include identification of seasonal and annual trends. The tool has great potential to be enriched with features that would calculate sea surface temperature and enhanced vegetation indices.

\section{References}

[1] Environmental Protection Agency, EPA, “Ambient Water Quality Criteria for Dissolved Oxygen, Water Clarity and 
Chlorophyll a for the Chesapeake Bay and Its Tidal Tributaries", Publication EPA903-R-03-002, Region III Water Protection Division, Philadelphia, Pennsylvania, April 2003.

[2] D. A. Flemer, "Continuous measurement of in vivo chlorophyll of a dinoflagellate bloom in Chesapeake Bay", Chesapeake Science 10, 1969, 99-103.

[3] D. A. Flemer, "Chlorophyll analysis as a method of evaluating the standing crop of phytoplankton and primary production. Chesapeake Science, 10, 1969, 301-306.

[4] L. W. Harding, E. Itsweire, and W. Esaias, Remote Sensing of Environment, Vol. 40, no. 2, pp. 79-100. May 1992.

[5] National Aeronautics and Space Administration, NASA, "Ocean Color Web", http://oceancolor.gsfc.nasa.gov, Accessed August 2006

[6] National Aeronautics and Space Administration, NASA, "EOS Data Product Levels", http://observer.gsfc.nasa.gov/sec3/ProductLevels.html,

Accessed August 2006.

[7] G. Dall'Olmo and A. A. Gitelson, "Effect of bio-optical parameter variability on the remote estimation of chlorophyll-a concentration in turbid productive waters: experimental results", Applied Optics, Volume 44, No 3, January 2005, pp. 412-422.

[8] National Aeronautics and Space Administration, NASA, "SeaWiFS post-launch calibration and validation analysis", NASA Technical Memorandum 2000-206892, NASA Goddard Space Flight Center, Greenbelt, Maryland, 2000.

[9] K. L.Carder, F. R. Chen, Z. Lee, S. K. Hawes, and J. P. Cannizzaro. "MODIS Ocean Science Team: Algorithm Theoretical Basis, Case 2, Chlorophyll a, Version7". http://modis.gsfc.nasa.gov/data/atbd/atbd mod19.pdf.

Accessed August, 2006

[10] T. A. Wool, R. B. Ambrose, J. L. Martin, E. A. Comer, "Water Quality Analysis Simulation Program (WASP)", http://www.epa.gov/athens/wwqtsc/WASP.pdf. Accessed August 2006.

[11] Marine Ecosystem Dynamics Modeling, MEDM, "Satilla River Estuary Water Quality Management System", http://fvcom.smast.umassd.edu/research projects/Satilla/wat erqualitymodel.html. Accessed August 2006.

[12] V. J. Alarcon and G. F. Sassenrath. "Synthetic imagery for visualization of crop canopy status", Proceedings of American Society for Photogrammetry and Remote Sensing (ASPRS) 2005 Annual Conference, Baltimore, Maryland, Vol. 5544, 178-185, March 7-11, 2005.

[13] K. L.Carder, F. R. Chen, Z. Lee, S.K. Hawes, and J. P. Cannizzaro, "MODIS Ocean Science Team: Algorithm
Theoretical Basis Document ATBD 19, Case 2, Chlorophyll a, Version 7'. College of Marine Science University of South Florida, St. Petersburg, Florida, 2003.

[14] EPA. "Water Quality Analysis Simulation Program (WASP)", $\quad$ http://www.epa.gov/athens/wwqtsc/WASP.pdf, accessed August 2006.

[15] D. H. Huddleston, W. L. Kingery, J. M. Kieffer, V. J. Alarcon, and W. Chen, 2003. "Development of a comprehensive water quality model of the St. Louis Bay estuary and watershed", EPA Gulf of Mexico Completion Report, Mississippi Department of Environmental Quality, Office of Pollution Control. Jackson, Mississippi, June 2003.

[16] P. A. Tester and J. T. Turner, "Comparative carbonspecific ingestion rates of phytoplankton by Acartia tonsa, Centropages velificatus and Eucalanus pileatus grazing on natural phytoplankton assemblages in the plume of the Mississippi River (northern Gulf of Mexico continental shelf)", Hydrobiologia, p. 167-168, Number 1, October 1988. 